\title{
ANÁLISE TEÓRICO-HISTÓRICA DAS PRODUÇÕES DE LEONTIEV E VIGOTSKI ACERCA DO DESENVOLVIMENTO DA MEMÓRIA
}

\author{
THEORETICAL HISTORICAL ANALYSIS OF LEONTIEV AND \\ VYGOTSKY'S PRODUCTIONS ON THE \\ DEVELOPMENT OF MEMORY
}

Sandro Henrique Vieira de Almeida ${ }^{1, *}$

RESUMO: No início da década de 1930, com a finalidade de analisar o livro O desenvolvimento da memória, escrito por Leontiev, ele e Vigotski escrevem um segundo prefácio, apresentando a obra, observando suas qualidades e discutindo alguns aspectos avaliados por eles como frágeis. O objetivo do presente artigo é realizar uma análise teórico-histórica de tal prefácio, destacando os procedimentos investigativos sobre a memória utilizados, as críticas realizadas pelos autores e a compreensão de memória dessa teoria.

Palavras-chave: Memória. Psicologia histórico-cultural. Vigotski. Leontiev. Desenvolvimento.

ABSTRACT: In the early 1930s, aiming at analysing Leontiev's book The development of memory, Leontiev and Vygotsky wrote a second preface to it, presenting the work, observing its qualities, and discussing some aspects they evaluated as fragile. The goal of this paper is to carry out a theoretical historical analysis of that preface, highlighting the investigative procedures applied about the concept of memory, the criticisms made by the authors and how the historical-cultural theory understood memory.

Keywords: Memory. Historical-cultural psychology. Vygotsky. Leontiev. Development.

1.Universidade Federal dos Vales do Jequitinhonha e Mucuri - Campus Diamantina (MG), Brasil.

*Autor correspondente: sandro.almeida@ufvjm.edu.br

Dossiê organizado por: Gisele Toassa e Ana Luiza Bustamante Smolka 


\section{Introdução}

Os primeiros anos que sucederam “a Revolução Russa, Outubro de 1917”, foram de provação para os povos que se lançaram naquele projeto ousado e inédito de construir uma nação que buscava superar os principais obstáculos presentes no modelo capitalista. Para aqueles que lutavam por aquele projeto, era necessária a criação de novas condições de vida, a fim de que os sujeitos pudessem se apropriar dos conhecimentos produzidos pelo humano, dos meios de sua produção e reprodução da realidade e, assim, de suas próprias vidas.

Muitos foram os caminhos e as formas que essa sociedade buscou para a construção desse projeto. Neste artigo, interessa-nos, especificamente, o projeto a que um grupo de psicólogos se lançou, no intuito de colaborar com os ideais do processo revolucionário em ebulição.

Tal grupo começou suas atividades em 1924, e, sob a liderança de Vigotski, realizou atividades que buscassem instruí-los na árdua tarefa de erigir uma nova teoria psicológica, a qual pudesse vir a superar as deficiências da ciência psicológica existente; uma teoria fundada nos marcos do materialismo histórico e dialético (VYGOTSKI, [1927]1997a).

Esse coletivo de jovens cientistas, liderados por Vigotski até seu falecimento, em 1934, foi constituído, inicialmente, tanto por Luria quanto por Leontiev, tendo, posteriormente, participação de Zankov e Sakharov e, logo após, de cinco novos membros: Bozhovich, Slavina, Morozova, Levina e Zaporozhets ${ }^{1}$.

Apesar do falecimento de Vigotski, esse autor continua sendo importante referência para os demais autores do grupo, e os princípios norteadores da teoria, ali elaborados, continuam fundantes das obras que se seguem e da teoria ainda hoje em desenvolvimento.

$\mathrm{Na}$ busca por compreender o psiquismo, foram realizadas investigações envolvendo diversos aspectos dele constitutivos, entre os quais estão as diversas funções psicológicas e a formação da personalidade, assim como o papel do processo educativo na formação dos indivíduos e na construção de uma sociedade tal qual a objetivada pela revolução bolchevique.

É importante destacar que partes dessas investigações sobre a memória estão presentes na produção de Vigotski por meio de exemplos e proposições teóricas deles derivadas. O cerne da discussão acerca da produção do grupo passa a ser a investigação sobre formação e diferenciação entre funções psicológicas elementares, ou naturais e funções superiores, bem como as relações dessas com o controle voluntário do comportamento.

No amplo leque de pesquisas sobre processos psíquicos realizadas naqueles anos, a função psicológica memória foi uma das que receberam maior atenção, estando o ápice dos estudos sobre ela situado entre os anos 1927 e 1932, predominantemente sob direção de Leontiev. Os resultados dessas pesquisas podem ser encontrados em um livro publicado em 1932, embora finalizado algum tempo antes, em 1929.

Por tudo isso, o objetivo deste artigo é analisar teórica e historicamente o segundo prefácio do livro de Leontiev acerca da memória, escrito por esse autor e por Vigotski, considerando o momento de sua publicação, em 1932. Com esse objetivo, usamos como referências para a análise tanto o primeiro prefácio de Vigotski para o livro, escrito em 1931, quanto a produção da psicologia histórico-cultural sobre memória e psiquismo em sua primeira década de formação, entre 1924 e 1934.

É relevante destacar que esta análise fundamenta-se no materialismo histórico e dialético e na compreensão de que as produções de Vigotski, de Leontiev e de Luria compartilham mesmas linhas epistemológica, teórica, investigativa e prática, o que não implica ausência de divergências entre suas produções. A ciência, como bem defendeu esses autores, faz-se também nas contradições e discordâncias, não somente nas linearidades e concordâncias. As relações entre tais autores não foram somente harmônicas, mas também ziguezagueantes, como é a vida. 


\section{A Investigação da Função Psicológica Memória}

A memória foi, desde o início da psicologia, uma das funções psicológicas mais bem exploradas. A primeira investigação sobre memória na história da psicologia científica ocorreu na Alemanha, foi conduzida por Ebbinghaus, e publicada como livro em 1885, sob o título Memória (EBBINGHAUS, 1964). Essa pesquisa foi pautada na escola de psicologia experimental alemã, entendendo que os processos psicológicos superiores poderiam, em experimentação, ser controlados e mensurados, sendo a introspecção experimental o método mais confiável e sendo Ebbinghaus o único sujeito de sua pesquisa.

Ebbinghaus - seguindo a epistemologia positivista - propôs estudar a memória sem a interferência do pensamento e das emoções e, para tanto, elaborou um instrumento de pesquisa formado por sílabas sem sentido (no idioma alemão). Tendo esses critérios como referência, Ebbinghaus elaborou 2.300 sílabas, as quais formaram o material de teste. Com os resultados desse procedimento, Ebbinghaus desenvolveu um rico trabalho, demonstrando a organização básica do esquecimento e da memorização mecânica por repetição (EBBINGHAUS, 1964).

Além desse pesquisador, outros autores realizaram estudos sobre memória naqueles anos, como Titchener e James, nos Estados Unidos, Ribot e Janet, na França, e Stern e Lewin (com Zeigarnik), na Alemanha, utilizando processos investigativos cuja organização fugia pouco aos marcos da psicologia da época e da epistemologia positivista.

O projeto de psicologia elaborado pelo grupo de cientistas liderados por Vigotski durante a década de 1920, por sua vez, delineia os pressupostos e objetivos centrais da emergente psicologia históricocultural, destacando "o conceito de função psíquica superior, o conceito de desenvolvimento cultural da conduta e o domínio dos próprios processos de comportamento" (VYGOTSKI, [1931]2000, p. 19, grifos nossos), os quais são chave para a humanização dos indivíduos. No segundo prefácio para $O$ desenvolvimento da memória, apresentado neste dossiê, Vigotski e Leontiev ratificam a proposição da teoria, ao escreverem que:

A ideia principal deste livro - e, ao mesmo tempo, de todos os estudos entre os quais ele adquire seus sentido e significado verdadeiros - consiste no reconhecimento do desenvolvimento histórico da personalidade humana e de suas funções psicológicas. Em essência, a assim chamada "teoria do desenvolvimento histórico" (ou histórico-cultural), em psicologia, designa uma teoria das funções psicológicas superiores (memória lógica, atenção voluntária, pensamento verbal, processos voluntários etc.) - nem mais, nem menos.A origem e o desenvolvimento das funções psicológicas superiores, suas estrutura e composição, sua forma de atividade e suas relações de dependência, as leis que regem seu curso e seu destino: esses são o conteúdo exato e o objeto verdadeiro desses estudos (VIGOSTSKI; LEONTIEV, [1932]2020, neste dossiê).

Assim sendo, uma das preocupações centrais do grupo nesse período foi a investigação das funções psíquicas superiores mediatas, ou seja, aquelas especificamente humanas, as quais, para se desenvolverem, demandam a apropriação, pelos sujeitos, dos conhecimentos historicamente acumulados pela humanidade, possibilitada pelas e nas relações que o sujeito tem com o mundo.

Destaca-se que a metodologia experimental foi um dos elementos centrais para a construção da psicologia histórico-cultural a partir do marxismo, mas que havia necessidade de despir-se do modelo positivista e, consequentemente, de construir um conjunto de procedimentos diferenciados daqueles existentes até então. 
Psicologia materialista nos requer mais que a incorporação dialética dos princípios materialistas para fundamentar os problemas psicológicos ou exemplificar os princípios de dados psicológicos concretos: o método dialético deve tornar-se o método de análise psicológico. Neste sentido, a psicologia contemporânea não pode descansar tranquila com a simples interpretação de sua matéria do ponto de vista subjetivo enquanto se acomoda em dados da velha psicologia empírica; ela deve, na verdade, estudar seu material por meio do método dialético, que deve ser o de desempenhar papel central, dominando outros métodos mais específicos (LEONT'EV, [1929]1977, p. 53-54).

A importância do experimento detalhado no livro de Leontiev para a psicologia histórico-cultural é avaliada, neste artigo, a partir de dois aspectos, concomitantemente. O primeiro é poder conhecer melhor a construção dos métodos de investigação, de seus caminhos teóricos e criativos; o segundo, a análise teórica e histórica da construção dos primeiros alicerces da abordagem em criação, por meio da análise do segundo prefácio.

A necessidade de a experimentação ser base da construção teórica é evidenciada no segundo prefácio e já está presente na proposição dos autores soviéticos. Tais autores desenvolveram uma série extensa de experimentos e análises, pois a experimentação é "o único caminho pelo qual podemos pesquisar por dentro nos padrões dos processos psicológicos superiores” (VYGOTSKY, [1930]1999, p. 43). Essa experimentação deve apreender tanto o movimento quanto o desenvolvimento dos processos psíquicos, suas formações e transformações. Para cumprir esse objetivo, é preciso estudar "a memória partindo de sua evolução histórica" (VYGOTSKI, [1931]1997c, p. 116), sendo que "[e]studar algo historicamente significa estudá-lo em movimento. Esta é a exigência fundamental do método dialético” (VYGOTSKI, 2000, p. 67).

\section{As Análises de Vigotski e Leontiev do Livro O Desenvolvimento da Memória}

A publicação do livro O desenvolvimento da memória foi uma grande conquista do grupo de estudiosos soviéticos em questão, visto que papel era um recurso escasso na União Soviética naqueles anos. Assim, apesar do atraso na publicação do livro, ele acabou permitindo maior consolidação das proposições do grupo e a avaliação da obra, fornecendo um rico panorama para a análise dos acertos e equívocos de suas produções científicas.

$\mathrm{Na}$ tentativa de melhor apreender esse momento do grupo liderado por Vigotski, é relevante analisar não apenas correções, esclarecimentos e complementações presentes no segundo prefácio do livro de Leontiev, mas também como o próprio grupo buscou superar essas problemáticas antes mesmo da publicação do segundo prefácio.

Dessa maneira, os autores não buscam, com esse segundo prefácio, um revisionismo da produção de Leontiev, mas a identificação de problemas percebidos, observando que tais problemas não são cruciais para o entendimento da obra e, assim, não a inutilizam. Analisando o texto de Leontiev ([1931]1981), bem como vários escritos de Vigotski que citam os estudos apresentados no texto (p. ex., VYGOTSKI, 2000, 1996, [1930]1997b; VYGOTSKY; LURIA, [1930]1996), é possível evidenciar algumas de suas mais importantes proposições e observar a relevância desses estudos na construção dos principais elementos teóricos sobre o desenvolvimento do psiquismo da psicologia histórico-cultural. Tais proposições são:

a. A utilização da comparação (identificação de diferenças e similaridades) como meio investigativo para entender a formação da memória tipicamente humana. Com esse objetivo, o autor destaca 
a necessidade da investigação anatomofuncional do encéfalo humano durante seu período de desenvolvimento até a emergência do Homo sapiens e em seu desenvolvimento atual, bem como da análise comparativa com os demais animais. A defesa da investigação do desenvolvimento orgânico é indispensável em toda a produção da psicologia histórico-cultural, tendo em vista não apenas a importância desse aspecto na compreensão da materialidade, mas também a indissociabilidade organicossocial defendida por essa abordagem;

b. A investigação acerca da memória, desde sua gênese, empregando, como sujeitos experimentais, tanto crianças quanto adolescentes e adultos, na busca por informações que possam auxiliar no entendimento desse processo em sua historicidade. O processo sempre consiste em entender cada momento em si mesmo e em sua relação com o todo;

c. A realização de experimentos utilizando palavras (e mesmo frases) com sentido: com esse procedimento, entre outros, os autores dão um importante passo para romper com a ideia de neutralidade científica e com outras premissas positivistas presentes ainda hoje nas investigações sobre memória, que utilizam palavras sem sentido como principal procedimento experimental;

d. A realização de experimentos com uso de auxílio (dicas/instrumentos);

e. A exposição de elementos-chave para a formação do sistema psicológico (ou sistema funcional, como aparece neste segundo prefácio) $)^{2}$.

Outro procedimento investigativo que merece relevo é realizado com o auxílio de cartões-dica (ou, em outros experimentos, de outros tipos de auxílio). Esse tipo de experimento é um bom exemplo do uso de instrumentos como modo de o sujeito realizar atividades que, de maneira independente, não conseguiria. A partir desse procedimento, nota-se claramente que o conceito de zona de desenvolvimento próximo estava em gestação. Seu uso já estava presente nas investigações e nas teorizações - a importância dada à teleologia mostra isso -, mas sua formalização e seu melhor acabamento ocorreriam somente nos anos de 1932 e 1933.

O experimento com cartões-dica foi mais exposto e seu delineamento pode ser encontrado em diversas publicações (VYGOTSKI, 2000, p. 256; 1996, p. 147; VYGOTSKI; LURIA, 1996, p. 194; LEONT’EV, [1932]1994, p. 306; LEONTYEV, 1981, p. 355)3. Um de seus produtos mais relevantes foi um gráfico denominado "paralelograma do desenvolvimento da memória", ou, em outros textos, "paralelogramo do desenvolvimento", o qual teve como objetivo demonstrar experimentalmente o processo de internalização das funções psicológicas superiores e a inter-relação memória-pensamento, tendo como sujeitos de crianças a adultos.

Em seu trabalho sobre a memória, Leontiev estabelece uma relação da memória com o pensamento, indicando que, com o desenvolvimento de ambos os processos, a memória vai se tornando cada vez mais intencional, tendendo a aproximar-se do pensamento, até o momento em que há fusão desses processos com a formação da memória lógica, sendo essa proposição central para a compreensão dos processos necessários à formação da singularidade de um sujeito, de sua personalidade.

Entretanto, na busca por responder as questões levantadas em seu estudo, Leontiev apresenta uma explicação que não cumpre com a proposição do texto acerca da superação do idealismo vigente, falha identificada no segundo prefácio:

Nessa luta ideológica contra as teorias idealistas e mecanicistas da memória, observa-se muitas vezes que o autor nem sempre desenvolve o sistema de seus pontos de vista fundamentais com suficientes coerência e clareza, o que, muitas vezes, causa erros de interpretação e compreensão de seu livro. 
Assim, partindo da premissa correta de que o desenvolvimento histórico das formas superiores da memória não substitui, mas remove as formas elementares de memorização, que são fundamentalmente um produto da evolução biológica, o autor, no entanto, em vários trechos de seu livro, apresenta seu pensamento e os resultados dos experimentos de tal modo que enfatiza unilateralmente a distinção entre as formas elementares e superiores da memória, sem destacar unidade, ligação e continuidade no desenvolvimento delas. Vários trechos de seu trabalho, portanto, podem ser lidos e compreendidos exatamente no espírito da substituição, em vez da remoção das formas inferiores de memória pelas superiores (VIGOTSKI; LEONTIEV, [1932]2020, p. 115-116).

A passagem citada já indica o primeiro ponto crítico identificado pelos autores do segundo prefácio em partes do texto de Leontiev: a possibilidade de compreender que as funções mais complexas, em seu desenvolvimento, substituem (em vez de remover) as formas mais elementares e, como consequência, a perda do movimento dialético desse processo torna-o mecânico, comprometendo a compreensão do desenvolvimento do sujeito. Na sequência do texto, os autores indicam também que Leontiev compreendeu corretamente o processo "no espírito da substituição" (VIGOTSKI; LEONTIEV, 2020).

Como apresentado por Vigotski e Leontiev, o desenvolvimento das funções psicológicas superiores não extingue as funções psicológicas elementares, assim como as funções psicológicas superiores internas não anulam as externas, visto que não há dissociação entre natural e social, entre os processos elementares e os superiores.

O que ocorre é um domínio das formas superiores sobre as inferiores devido às diferenças qualitativas entre suas estruturas. Assim sendo, há superação por incorporação, como bem-indicado pelos autores ao mencionarem o termo alemão aufheben ${ }^{4}$. Nas palavras de Vigotski, "as formas inferiores não se aniquilam, mas se incluem na superior e continuam existindo nela como instância submetida" (VYGOTSKI, 2000, p. 129).

Continuando a análise, Vigotski e Leontiev apresentam outro ponto falho na proposição da relação entre pensamento e memória e da formação da memória lógica como parte de um sistema funcional. Dizem os autores:

o desvelamento da memória lógica como sistema funcional complexo de processos psicológicos em toda a singularidade de suas construção e atividade permaneceu como tarefa não realizada nas páginas deste livro. De igual maneira, o problema teórico e genético extremamente complexo da unidade do interno e do externo e da transição do externo para o interno no processo de desenvolvimento social da criança (um problema que foi tão intimamente abordado por experimentos que estudam a transição dos processos de memória mediados externamente para processos mediados internamente) não foi resolvido integralmente dentro deste estudo (VIGOTSKI; LEONTIEV, [1932]2020, p. 118).

Apesar de Leontiev apresentar, em seu texto, a relação entre pensamento e memória e a formação da memória lógica (identificando-a como sistema funcional), esse processo ainda não havia sido relacionado como parte da formação do sistema psicológico, elaboração essa que ganha corpo na produção de Vigotski sobre o tema a partir de 1930, como a discussão sobre o processo de internalização das funções psicológicas.

Vigotski, atento à materialidade e à dialética da internalização dos processos psíquicos, sintetiza bem os resultados das investigações do desenvolvimento histórico das funções psicológicas superiores, defendendo que o processo de internalização deveria ser chamado processo de revolução, visto que há um salto qualitativo de uma estrutura para outra, a superação de um ponto nodal. 
Tal autor entende que há uma radical reestruturação da atividade psíquica e, com isso, há “1) uma substituição de funções; 2) mudança nas funções naturais [...];3) o aparecimento de novos sistemas psicológicos, funcionais (ou funções sistêmicas)” (VYGOTSKY, 1999, p. 55).

Ampliando um pouco mais a explicação do processo de internalização, Vigotski diz que:

[o] desenvolvimento, como frequentemente acontece, não se move em círculo [...], mas ao longo de uma espiral, retornando em um plano superior a um ponto em que já passou.

Nós chamamos esta retirada da operação interna, esta internalização das funções psicológicas superiores conectadas com novas mudanças em sua estrutura, processos de revolução, tendo em mente principalmente o seguinte: $o$ fato de as funções psicológicas superiores serem construídas inicialmente como uma forma externa de comportamento e dependerem de um signo externo não é de forma alguma acidental, mas, ao contrário, é determinado pela natureza psicológica externa da função superior, que, como havíamos dito acima, não se origina como uma continuação direta dos processos elementares, mas é um método de comportamento aplicado no próprio indivíduo (VYGOTSKY, 1999, p. 53).

As funções psicológicas internalizadas ficam cada vez mais interligadas; há uma mudança na relação existente entre as funções superiores, modificando a estrutura funcional da consciência e formando um novo sistema psicológico, caracterizado por intrínseca interconexão e inter-relação das funções. É esse sistema que dá ao indivíduo a percepção de totalidade do psiquismo.

Essa discussão está relacionada a outro ponto crítico apresentado no segundo prefácio - a função do cérebro humano -, ressaltando a necessidade de compreender o papel do biológico em todo esse processo, observando a indissociação biológico-social e a materialidade da formação do psiquismo. Esse aspecto é deixado, em alguns momentos, de fora da análise, o que contribui para um entendimento que "pode levar à separação entre os processos de desenvolvimento da memória e os processos de desenvolvimento do cérebro e de suas funções (separação entre a função psicológica e seu substrato material)" (VIGOTSKI; LEONTIEV, 2020, p. 117).

Nesse ponto, não é exagero ressaltar que o entendimento materialista histórico e dialético da relação cérebro-psiquismo encontra-se na afirmação de que a fonte do psiquismo está no conjunto de relações sociais, não no cérebro. Assim sendo, o substrato do ideal é material - a realidade apreendida pela sensibilidade é auxiliada e possibilitada pelo cérebro na atividade material real.

Dessa maneira, pode-se dizer que esse é "um sistema que não somente amplia infinitamente as capacidades adaptativas da memória e transforma a memória animal em memória humana, mas que, organizado de outra maneira, é regido por suas próprias leis peculiares" (VIGOTSKI; LEONTIEV, 2020, p. 117).

Isto posto, é patente que os autores mantiveram seus próprios estudos em constante questionamento, permitindo que as obras posteriores pudessem corrigir ou consolidar posições anteriormente defendidas e indicando a experiência em suas produções da epistemologia de referência.

Considerando a produção de Leontiev, associada aos demais textos de Vigotski e às proposições dos autores no segundo prefácio, faz-se mister ressaltar que, para essa teoria, no início de sua história ontogenética, o sujeito é tão somente um candidato à humanização; ou seja, torna-se humano ao apropriar-se da produção dos humanos (MARX, [1844]1987). Para humanizar-se, o indivíduo deve desenvolver suas funções psicológicas superiores e, assim, tornar-se cada vez mais livre, cada vez mais independente de suas necessidades naturais. 
Assim, "a natureza psíquica do homem vem a ser um conjunto de relações sociais deslocadas para o interior e convertidas em funções da personalidade e em formas de sua estrutura” (VYGOTSKI, 2000, p. 151).

\section{Considerações Finais}

O segundo prefácio, escrito por Vigotski e Leontiev em 1932 para o livro O desenvolvimento da memória de Leontiev, é um documento ímpar, pois mostra não apenas quão argutos foram os autores fundantes da psicologia histórico-cultural, mas principalmente o quanto a construção da ciência psicológica, erigida sobre os marcos do materialismo histórico e dialético, foi realizada com o cuidado e a criticidade que o projeto exigia, sendo constantes a revisão da literatura psicológica existente no mundo e o rigor na elaboração e na análise dos procedimentos experimentais: É a síntese de todos esses elementos, somados à efervescência do processo revolucionário, que possibilitou a construção de uma teoria sólida e suficiente para continuar em movimento, para assim ser concreta.

Esse projeto sobre a memória (entre outros) permitiu aos autores da psicologia histórico-cultural a elaboração de um conjunto rico de informações, as quais lhes permitiram consolidar alguns de seus principais pressupostos. Neste artigo, destacamos o amplo uso de procedimentos experimentais, o processo de formação do sistema psicológico e o melhor entendimento da formação das funções psíquicas superiores.

Como já mencionado, essa formação propicia uma radical reestruturação da atividade psíquica, pois há modificação nas funções naturais, substituições de funções, e, ao longo do desenvolvimento, há a mudança de um processo antes interpsíquico para outro intrapsíquico. É justamente essa estrutura qualitativamente nova que permite aos seres humanos a ampliação do controle de seu próprio comportamento.

Por fim, vale novamente ressaltar que os estudos e as proposições realizados nesse momento são uma importante trilha, pela qual o grupo de autores seguiu dentro da ciência soviética; um caminho tortuoso, repleto de intrigas, perseguições, mortes, guerra e cesura. No entanto, esse caminhar também propiciou amizades, conquistas, descobertas e criatividade, construindo uma teoria viva e pulsante, com uma vasta gama de possibilidades teóricas e práticas, cujo critério de verdade está na prática social.

\section{Notas}

1. Há um conjunto grande de literatura sobre esse momento da psicologia histórico-cultural soviética, com uma relevante variação de análise sobre o período e os anos posteriores à morte de Vigotski. Entre as obras, tem-se: Brožek e Slobin (1972); Garcia Vegas (1993), Luria ([1976]1992), McLeish (1975), Rahmani (1973), Shuare (1990) e Tuleski (2002).

2. Os itens d e e serão trabalhados em conjunto.

3. Além das referências indicadas, há a apresentação de um destes experimentos no capítulo sobre o desenvolvimento da memória e do pensamento no livro A formação social da mente (VIGOTSKI, 2000, p. 51).

4. Em um texto anterior, Vigotski também recorre a Hegel para explicar o processo de superação por incorporação: “Hegel recorda o duplo sentido da palavra alemã 'superar' (snimat) [aufheben, em alemão]. Entendemos por ela, disse ele, em primeiro lugar, 'suprimir', 'negar', e dizemos em consequência: 'A lei tem sido suprimida', 'essa instituição foi suprimida', mas significa também 'conservar', e se a utiliza no sentido de que algo se conserva. Semelhante dualidade da palavra não deve ser considerada casual: reflete a relação efetiva, objetiva, que está subjacente no processo de desenvolvimento no qual cada estágio superior nega o inferior, mas o nega sem destruí-lo, senão incluindo-o como categoria superada, como momento integrante" (VYGOTSKI, 1996, p. 118-119). 


\section{REFERÊNCIAS}

ALMEIDA, S. H. V. O conceito de memória na obra de Vigotski. 2004. Dissertação (Mestrado em Educação: Psicologia da Educação) - Pontifícia Universidade Católica (PUC-SP), São Paulo, 2004. 149 p.

ALMEIDA, S. H. V. Psicologia histórico-cultural da memória. 2008. Tese (Doutorado em Educação: Psicologia da Educação) - Pontifícia Universidade Católica de São Paulo (PUC-SP), São Paulo, 2008. 277 p.

BROŽEK, J.; SLOBIN, D. I. (orgs.) Psychology in the USSR: An historical perspective. White Plains: IASP, 1972 .

EBBINGHAUS, H. Memory: A contribution to experimental psychology. New York: Dover, 1964.

GARCIA VEGAS, L. Historia de la psicología: La psicología rusa: reflexología y psicología soviética. México: Siglo XXI, 1993, v. iii.

LEONT'EV, A. N. (1929).The dialectical method in the psychology of memory. Soviet Psychology, v. XVI, n. 1, Fall, p. 53-69, 1977.

LEONTYEV, A. N (1932). The development of voluntary attention in the child. In: VAN DER VEER, R.; VALSINER J. The Vygotsky reader. Oxford: Blackwell, 1994, p. 289-312.

LEONT'EV, A. N (1931). The development of higher forms of memory. In: LEONTYEV, A. N. Problems of the development of the mind. Moscow: Progress, 1981, p. 327-364.

LURIA, A. R. (1976). A construção da mente. São Paulo: Ícone, 1992.

MARX, C. (1844). Manuscritos económicos-filosóficos de 1844. Escritos de juventud. México: Fundo de Cultura Económica, 1987, p. 555-568.

McLEISH, J. Soviet Psychology: History, theory, content. London: Methuen \& Co. Ltd., 1975.

PUZIREI, A. A.; GUIPPENRÉITER, Y. (eds.) El proceso de formación de la psicología marxista: L. Vigotski, A. Leontiev, A. Luria. Moscú: Progreso, 1989.

RAHMANI, L. Soviet Psychology: Philosophical, theoretical and experimental issues. New York: International Universities Press, 1973.

SHUARE, M. La psicología soviética tal como yo la veo. Moscú: Progreso, 1990.

TULESKI, S. C. Vigotski: A construção de uma psicologia marxista. Maringá: Eduem, 2002.

VIGOTSKI, L. S. A formação social da mente. São Paulo: Martins Fontes, 2000.

VIGOTSKI, L. S.; LEONTIEV, A. N. (1931/1932). Prefácio para o livro de A.N. Leontiev O desenvolvimento da memória. Cadernos CEDES, Campinas, v. 40, n. 11, 2020

VYGOTSKI, L. S. (1931). Paidologia del adolescente. Obras Escogidas. Madrid: Visor/MEC, 1996, v. iv, p. $11-248$. 
VYGOTSKI, L. S. (1927). El significado histórico de la crisis de la psicología. Una investigación metodológica. Obras Escogidas. 2. ed. Madrid: Visor/MEC, 1997a, v. i, p. 259-413.

VYGOTSKI, L. S. (1930). Sobre los sistemas psicológicos. Obras Escogidas. 2. ed. Madrid: Visor/MEC, 1997b, v. i, p. 71-93.

VYGOTSKI, L. S. (1931). Prefacio al libro de A. N. Leontiev Desarrollo de la memoria. Obras Escogidas. Madrid: Visor/MEC, 1997c, v. i, p. 111-117.

VYGOTSKI, L. S. (1930). Tool and sign in the development of the child. The collected works of L. S. Vygotsky. New York: Kluwer Academic/Plenum Press, 1999, v. vi, p. 01-68.

VYGOTSKI, L. S. (1931). Historia del desarrollo de las funciones psíquicas superiores. Obras Escogidas. 2. ed. Madrid: Visor/MEC, 2000, v. iii, pp. 11-340.

VYGOTSKY, L. S; LURIA, A. R. (1930). Estudos da história do comportamento: Símios, homem primitivo e criança. Porto Alegre: Artes Médicas, 1996.

Recebido: 01 Jul 2019

Aceito: 30 Nov 2019

Comitê Editorial do Cedes/Coordenação deste número:

Silvia Cordeiro Nassif e Maria Silvia Pinto de Moura Librandi da Rocha 